\title{
Estratégias de uso de água salobra na produção de alface em hidroponia NFT
}

\author{
Márcio S. Alves ${ }^{1}$, Tales M. Soares ${ }^{1}$, Luana T. Silva ${ }^{1}$, Joseane P. Fernandes ${ }^{1}$, \\ Mariana L. A. 0 liveira $^{1} \&$ Vital P. S. Paz ${ }^{1}$
}

\begin{abstract}
RESUMO
Plantas de alface crespa 'Verônica' foram cultivadas em condições hidropônicas, objetivando avaliar três diferentes estratégias de emprego de águas salobras: 1) águas salobras para reposição das perdas por evapotranspiração (ETC) e água doce para o preparo da solução nutritiva (SN); 2) águas salobras para o preparo da SN e água doce para reposição da ETc; 3) águas salobras para o preparo da SN e reposição da ETC. O $\mathrm{s}$ níveis de salinidade da água foram obtidos pela adição de $\mathrm{NaCl}$ à água doce $\left(0,27 \mathrm{dS} \mathrm{m}^{-1}\right)$ : 1,$45 ; 2,51 ; 3,6 ; 5,41$ e $7,5 \mathrm{dS} \mathrm{m}^{-1}$. O experimento foi conduzido em quatro blocos aleatorizados, com quatro repetições por tratamento. U ma estrutura de pesquisa foi construída com 72 parcelas que simulam a técnica do fluxo laminar de nutrientes (NFT). 0 uso de áqua salobra apenas para repor a ETc não produziu efeito sobre a produção da alface. Por outro lado, o uso de águas salobras para o preparo da SN e áqua doce para reposição da ETc, reduziu o rendimento da alface (massa de matéria fresca da parte aérea) em $4,99 \%$ por ( $\left(\mathrm{SS} \mathrm{m} \mathrm{m}^{-1}\right.$ ). 0 rendimento foi reduzido em $7 \%$ por $\mathrm{dS} \mathrm{m}^{-1}$ quando águas salobras foram usadas tanto para o preparo da SN quanto para reposição da ETc. Apesar da redução linear da produção da alface com o aumento da salinidade da água, sintomas depreciativos para a qualidade da alface hidropônica não foram registrados.
\end{abstract}

Palavras-chave: salinidade, cultivo sem solo, hortaliças, águas subterrâneas, irrigação

\section{Strategies for use of brackish water in NFT hydroponic lettuce production}

\begin{abstract}
Plants of crisphead lettuce cv. 'Verônica' were grown under hydroponic conditions aiming to evaluate three different strategies of brackish waters utilization: 1) brackish waters to replace the evapotranspiration loss (ETC) and fresh water to prepare nutrient solution (NS); 2) brackish waters to prepare NS and fresh water to replace the ETc; 3) brackish waters to prepare NS and replace ETc. The levels of water salinity were obtained by addition of $\mathrm{N} \mathrm{aCl}$ to fresh water $\left(0.27 \mathrm{dS} \mathrm{m}^{-1}\right): 1.45 ; 2.51 ; 3.6 ; 5.41$ and $7.5 \mathrm{dS} \mathrm{m}^{-1}$. The experiment was conducted in randomized blocks with four replications per treatment. A research structure was built with 72 experimental units which simulate the nutrient film technique (NFT). The use of brackish water only to replace the ETc did not affect the lettuce yield. $\mathrm{O} n$ the other hand, the use of brackish waters to prepare NS, and fresh water to replace the ETc loss, reduce the lettuce yield (shoot fresh matter) by $4.99 \%$ per ( $\mathrm{dS} \mathrm{m}^{-1}$ ). The lettuce yield was reduced by $7 \%$ per $\mathrm{dS} \mathrm{m}^{-1}$ as brackish water was used to prepare NS and replace ETc loss. Despite the linear decline of lettuce yield as the water salinity increased, depreciative symptoms for quality of hydroponic lettuce were not registered.
\end{abstract}

Key words: salinity, soilless cultivation, vegetables, groundwater, irrigation 


\section{INTRODUÇÃO}

Na região Semiárida do Brasil a escassez hídrica afeta gravemente a população, ensejando graves perdas sociais e econômicas, refletidas na diminuição da capacidade produtiva, acentuando o desemprego, a concentração de renda e o empobrecimento de um contingente significativo da população.

No Semiárido a irrigação se torna uma das principais vias de desenvolvimento, sendo insofismável o papel dessa técnica, tanto na agricultura familiar quanto no agronegócio regionais. Entretanto, a irrigação também é reconhecidamente uma das principais causadoras de impactos ambientais negativos de origem antrópica no Semiárido. Nesse aspecto particular, a salinização do solo se torna um dos problemas mais graves e emblemáticos, tanto em projetos públicos quanto em privados. O problema da salinização pode ocorrer com o uso de água doce em condições de má drenagem do solo e de manejo incorreto da irrigação; com o emprego de águas salobras, o processo da salinização se torna catalisado e suas consequências potencializadas.

A depleção quantitativa e qualitativa dos recursos hídricos nos últimos anos tem conduzido à busca de técnicas para uso mais eficiente da água e também para aproveitamento racional de águas consideradas de qualidade inferior. Visando especificamente uma alternativa para comunidades isoladas do Semiárido, onde a escassez de água doce se torna um problema ainda mais dramático, algumas pesquisas recentes têm sugerido a técnica da hidroponia. Além de poder permitir melhor eficiência no uso da água, devido à redução das perdas por evaporação, a hidroponia pode amplificar a vantagem da irrigação localizada, no que diz respeito ao menor efeito da salinidade sobre as plantas, reduzindo ainda os riscos ambientais associados ao acúmulo de sais no ambiente.

Pelas dificuldades técnicas e orçamentárias de se recalcar águas superficiais até as comunidades difusas no território do Semiárido, as águas subterrâneas são uma opção razoável. No entanto, em função das características climáticas e geológicas essas águas são frequentemente salobras e exploradas em vazões menores que $4 \mathrm{~m}^{3} \mathrm{~h}^{-1}$ (Audry \& Suassuna, 1995; Costa et al., 2006), dificultando a irrigação convencional.

Portanto, o uso intensivo da água na hidroponia pode ser condizente com as características quantitativas e qualitativas das águas subterrâneas disponíveis às populações difusas do Semiárido. Neste sentido, pesquisas recentes vêm sendo realizadas com o intuito de avaliar a viabilidade de aproveitamento de águas salobras em cultivos hidropônicos (Santos et al., 2010a, 2010b; Paulus et al., 2010; Soares et al., 2010; Dias et al., 2010; Amorim et al., 2005). Esses estudos têm a premissa de que na hidroponia a resposta das plantas em condições salinas é melhor que no solo devido à ausência do potencial mátrico, que é uma das causas da diminuição da energia livre de água (Soares et al., 2007). Além disso, sistemas hidropônicos do tipo fechado, como o NFT (técnica do fluxo laminar de nutrientes), já funcionam como sistema de irrigação e também de drenagem, permitindo o destino apropriado dos sais, ao final da produção.

Por ser a hortaliça folhosa mais consumida no Brasil, a alface se destaca também no cenário nacional dos cultivos hidropônicos, chegando a ser responsável por $80 \%$ desse tipo de produção. Obviamente, não é possível transpor, para hidroponia, os limites de tolerância da alface à salinidade, estabelecidos para a agricultura convencional em solo.

Alguns autores apontam a alface hidropônica como tolerante à salinidade, podendo até ocorrer efeito benéfico dos sais ao proporcionarem maior firmeza às plantas (Rodrigues, 2002). Este é um dado interessante, pois na agricultura convencional a alface é classificada como moderadamente sensível à salinidade do solo, pela FAO (Ayers \& Westcot, 1999), sendo seu rendimento potencial alcançado quando a condutividade elétrica do extrato de saturação do solo atinge o valor limiar de $1,3 \mathrm{dS} \mathrm{m}^{-1}$; acima deste valor se espera uma redução de $13 \%$ no rendimento da alface, por acréscimo unitário da salinidade em $\mathrm{dS} \mathrm{m} \mathrm{m}^{-1}$.

Estudos sobre a utilização de águas salobras em sistemas hidropônicos têm tratado de distintas estratégias de uso dessas águas associadas ou não a uma fonte de água doce. Soares et al. (2010) estudaram o uso de águas doce e salobra, alternandoas no preparo da solução nutritiva ou na reposição da evapotranspiração em sistema hidropônico, mas seus experimentos foram realizados em períodos diferentes. Por outro lado, Paulus et al. (2010) e Santos et al. (2010a e b) investigaram a utilização de águas salobras, tanto no preparo da solução nutritiva como na reposição da evapotranspiração, mas não o uso combinado com água doce.

Diferentes estratégias de uso de águas salobras, associadas ou não com água doce, devem produzir efeito no rendimento das culturas hidropônicas. A comparação dos resultados obtidos a partir de diferentes estratégias não deveria ser conduzida a partir de pesquisas estabelecidas em condições distintas de cultivo (região, tipo de ambiente protegido, clima local, estação do ano, manejo da irrigação, etc.), considerandose as diversas variáveis que têm interação com a salinidade sobre as respostas das culturas.

Neste contexto, o objetivo do presente trabalho foi avaliar a viabilidade técnica da produção de alface crespa 'Verônica', com três diferentes estratégias de uso de águas salobras, quais sejam: uso exclusivo de água salobra; uso de água salobra na produção da solução nutritiva e água doce na reposição da evapotranspiração; uso de água doce na produção da solução nutritiva e água salobra na reposição da evapotranspiração.

\section{Material E MÉTOdos}

O experimento foi realizado no período de 15 de julho a 05 de setembro de 2009, em casa de vegetação, em arco, do tipo geminada, apresentando $32 \mathrm{~m}$ de comprimento, $14 \mathrm{~m}$ de largura e 4 m de pé direito e coberta com filme plástico, anti UV, de 150 $\mu \mathrm{m}$ de espessura, sendo as laterais constituídas de telas de cor branca. Na altura do pé direito foi instalada internamente uma manta termorrefletora para controle da radiação e temperatura.

O experimento foi desenvolvido na Universidade Federal do Recôncavo da Bahia, no Município de Cruz das Almas, a $12^{\circ} 40^{\prime} 19^{\prime \prime}$ de latitude sul, 39 $06^{\prime} 23^{\prime \prime}$ de longitude oeste e altitude média de $220 \mathrm{~m}$. O clima da região é classificado como 
úmido a subúmido, com umidade relativa anual e temperatura média anual de $80 \%$ e $24,1^{\circ} \mathrm{C}$, respectivamente, apresentando pluviosidade média anual de $1.170 \mathrm{~mm}$ (Almeida, 1999).

Os dados de temperatura e umidade relativa no ambiente protegido foram monitorados utilizando-se um termohigrômetro, da Instrutherm, modelo HTR-157, instalado a 2 metros de altura e programado para medições a cada 15 minutos.

Foram construídas 72 unidades experimentais (Soares et al., 2009). Cada parcela representava um sistema hidropônico NFT (técnica do fluxo laminar de nutrientes) independente, composto de um reservatório plástico com capacidade para $60 \mathrm{~L}$ de solução nutritiva; uma eletrobomba de circulação e um perfil hidropônico em polipropileno com aditivo anti-ultravioleta, com diâmetro comercial de $100 \mathrm{~mm}$, comprimento de $3 \mathrm{~m}$, contendo 9 orifícios de $2,5 \mathrm{~cm}$ de raio, espaçados a cada $0,3 \mathrm{~m}$.

Os perfis foram instalados em pares a uma altura de $1 \mathrm{~m}$ da superfície do solo, possuindo quatro pontos de apoio e uma inclinação de $4 \%$. Entre os perfis o espaçamento foi de $0,5 \mathrm{~m}$. Entre os pares de parcelas, foi deixado um corredor de $0,90 \mathrm{~m}$ de largura para facilitar o trânsito e a operacionalidade. $\mathrm{O}$ piso foi coberto com manta geotêxtil cinza, visando melhorar a higiene, aumentar a vida útil das eletrobombas e melhorar as condições fitossanitárias.

Também foram montados sistemas de abastecimento automático individualizados para cada parcela, construídos com tubulação de PVC de seção contínua e diâmetro nominal de 0,2 $\mathrm{m}$. Este tipo de sistema permite a saída automática de água para o reservatório de solução nutritiva mediante uma torneira-bóia, possibilitando a manutenção do volume e a concentração da solução apropriada para cada tratamento.

Foi avaliada a variedade de alface crespa 'Verônica', da SAKATA. Sementes peletizadas foram semeadas em espuma fenólica com células de 2 × 2 × 2 cm no dia 15 de julho de 2009 e, após $32 \mathrm{~h}$ em ambiente sem iluminação, foram transferidas para o berçário, onde permaneceram 23 dias. Inicialmente, as mudas foram irrigadas apenas com água e, do oitavo dia até o décimo quinto dia, com solução nutritiva padrão diluída a 50\%; a partir daí foram irrigadas com solução nutritiva a $100 \%$ (formulação de Furlani et al., 1999); em seguida, as mudas foram transplantadas para a bancada de desenvolvimento, apresentando de 5 a $6 \mathrm{~cm}$ de altura e com cinco folhas definitivas, cultivando-se, em cada perfil, um total de cinco plantas.

Os tratamentos foram iniciados em seguida ao transplantio e consistiram em níveis de salinidade da água, caracterizados em termos de condutividade elétrica (CE). As águas utilizadas foram salinizadas artificialmente mediante adição de cloreto de sódio $(\mathrm{NaCl})$ à água doce $\left(0,27 \mathrm{dS} \mathrm{m}^{-1}\right)$ resultando em seis níveis de salinidade da água de acordo com cada tratamento (Tabela 1).

Os diferentes níveis de $\mathrm{CE}$ da água (CEa) foram analisados de acordo com três tipos de emprego de águas salobras, quais sejam: no tipo de uso I (UI), utilizou-se água doce (não salinizada) no preparo da solução nutritiva e água salobra na reposição da evapotranspiração (ETc), implicando em salinidades crescentes; no tipo de uso II (UII), a água salobra foi utilizada no preparo da solução nutritiva e a reposição da ETc foi feita com água doce, resultando em salinidade constante em cada tratamento e no tipo de uso III (UIII), utilizou-se
Tabela 1. Concentração de $\mathrm{NaCl}$ e condutividade elétrica da água (CEa) para os diferentes tratamentos aos quais foram submetidas as plantas de alface

\begin{tabular}{ccc}
\hline Tratamentos & $\mathbf{N a C l}\left(\mathbf{g ~ L}^{-1}\right)$ & CEa $\left(\mathbf{d S ~} \mathbf{~ m}^{-1}\right)$ \\
Testemunha & 0,000 & 0,27 \\
T1 & 0,585 & 1,45 \\
T2 & 1,170 & 2,51 \\
T3 & 1,755 & 3,60 \\
T4 & 2,925 & 5,41 \\
T5 & 4,095 & 7,50 \\
\hline
\end{tabular}

exclusivamente água salobra, tanto na solução nutritiva como na reposição da ETc.

A presente pesquisa foi conduzida em três diferentes experimentos separados na casa de vegetação, mas concomitantes.

Para cada tipo de uso o delineamento experimental foi o aleatorizado em blocos com seis tratamentos (Tabela 1) e cinco repetições. A solução nutritiva em todos os tratamentos foi preparada com a mesma quantidade de fertilizantes, seguindose a recomendação de Furlani et al. (1999) para o cultivo hidropônico da alface.

A solução nutritiva foi bombeada do reservatório até a parte mais alta da bancada pela eletrobomba de circulação, acionada por um temporizador digital programado para ligar o sistema durante15 min com intervalos de 15 min, no período das 06 às $11 \mathrm{~h}$ e das 14 às $19 \mathrm{~h}$; irrigação constante das 11 às $14 \mathrm{~h}$; e irrigações de $15 \mathrm{~min}$, às 21,23 e $02 \mathrm{~h}$.

Durante os experimentos foram coletadas, a cada dois dias, amostras da solução nutritiva para determinação e monitoramento da condutividade elétrica (CEsol) e do $\mathrm{pH}$.

A colheita da alface foi realizada aos 24 dias após o transplantio (DAT), sendo colhidas as três plantas centrais de cada perfil. Foram mensuradas as variáveis: massa de matéria fresca das folhas (MFF), massa de matéria fresca do caule (MFC), massa de matéria fresca da parte aérea (MFPA), determinadas em balança de precisão. Com o auxílio de uma régua graduada foram determinados o comprimento do caule (CC) (do ponto de corte até o ápice), o comprimento da raiz (CR) (do ponto de inserção caulinar até a ponta da raiz) e a circunferência da planta $(\mathrm{CP})$. Após pré-secagem por $24 \mathrm{~h}$, as plantas foram levadas à estufa de circulação forçada, na temperatura de $65^{\circ} \mathrm{C}$, até obtenção de massa constante no tempo. Os valores de massa de matéria seca da folha, da parte aérea e das raízes foram determinados em balança de precisão.

O fator salinidade da água foi estudado mediante análises de variância e de regressão. Os diferentes tipos de uso foram analisados mediante a porcentagem de redução das produções por acréscimo unitário da CEa. Todas as análises foram efetuadas no programa SAS.

\section{RESULTADOS E DISCUSSÃO}

De maneira geral, durante o período diurno a temperatura do ar foi superior à temperatura ideal, compreendida entre $15 \mathrm{e}$ $25^{\circ} \mathrm{C}$ (Martinez, 2006). Em certos momentos, foram verificadas temperaturas máximas acima da temperatura crítica para a alface 
$\left(>30^{\circ} \mathrm{C}\right.$ ) (Rodrigues, 2002), observando-se valor máximo de 37 ${ }^{\circ} \mathrm{C}$ (Figura 1). Em relação à umidade relativa do ar, a média registrada no período foi de $87 \%$, considerada acima do recomendado como faixa ideal, qual seja, de 60 a $80 \%$ (Martinez, 2006), porém no presente estudo não se constatou efeito maléfico da temperatura do ar nem da umidade relativa sobre o crescimento e desenvolvimento das plantas de alface.
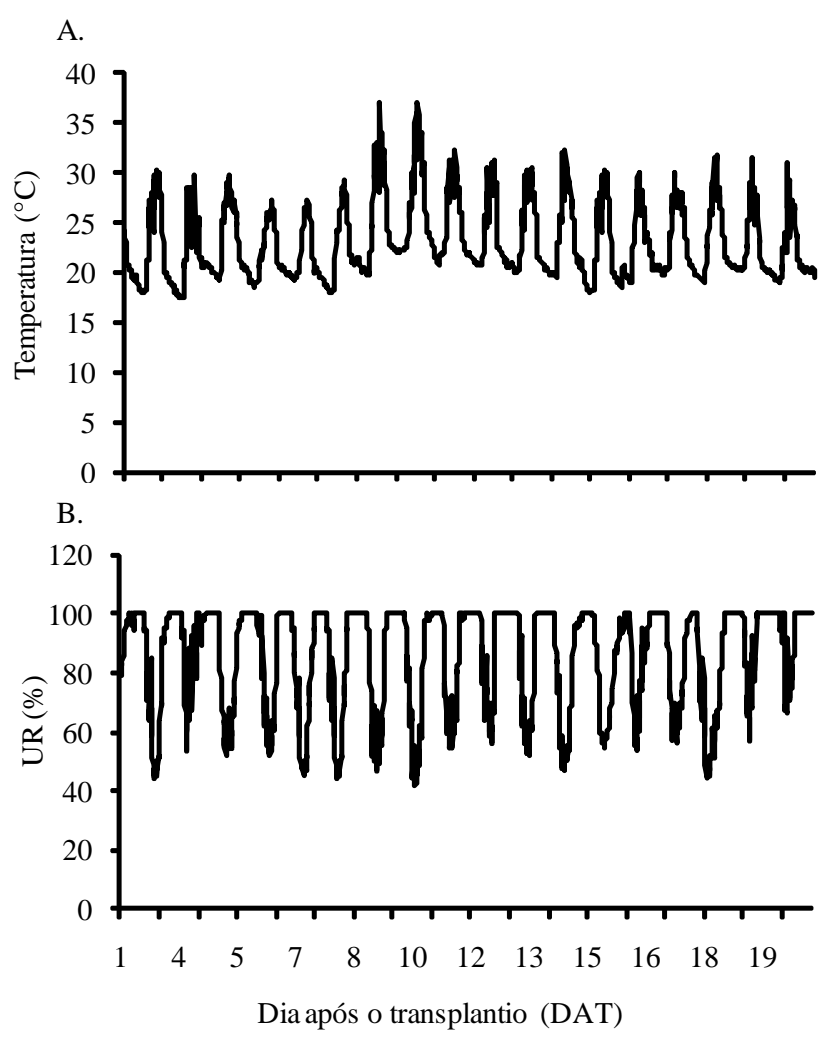

Figura 1. Temperatura do ar (A) e umidade relativa (UR) do $\operatorname{ar}(\mathrm{B})$ ao longo do ciclo da cultura

Em relação à produção das plantas-controle de alface 'Verônica', foi encontrada, no presente estudo, uma média de 339,55 g de massa de matéria fresca da parte aérea após 24 DAT. Utilizando a mesma cultivar, Paulus et al. (2010) produziram uma média de 359,60 g de MFPA colhidas aos 23 DAT; enquanto Soares et al. (2010) encontraram uma produção de aproximadamente 275 g colhida em 25 DAT. Produção semelhante foi encontrada por Casaroli et al. (2003), que obtiveram 278,8 g de MFPA em 30 DAT. Esses resultados exemplificam que as plantas controle do presente estudo produziram dentro do esperado para a cultivar 'Verônica'.

No tipo de uso I (Figura 2A), partiu-se de uma salinidade inicial igual para todos os tratamentos, já que a solução nutritiva foi preparada com água doce. A salinidade inicial medida com condutivímetro foi de $2,19 \mathrm{dS} \mathrm{m}^{-1}$. A aplicação dos tratamentos, ou seja, das águas salobras na reposição das perdas por evapotranspiração, alterou a salinidade do meio. Para a testemunha (água doce), a tendência foi de pequena redução da salinidade, o que era previsto devido o consumo de nutrientes ser maior que o aporte de sais dissolvidos nessa água.

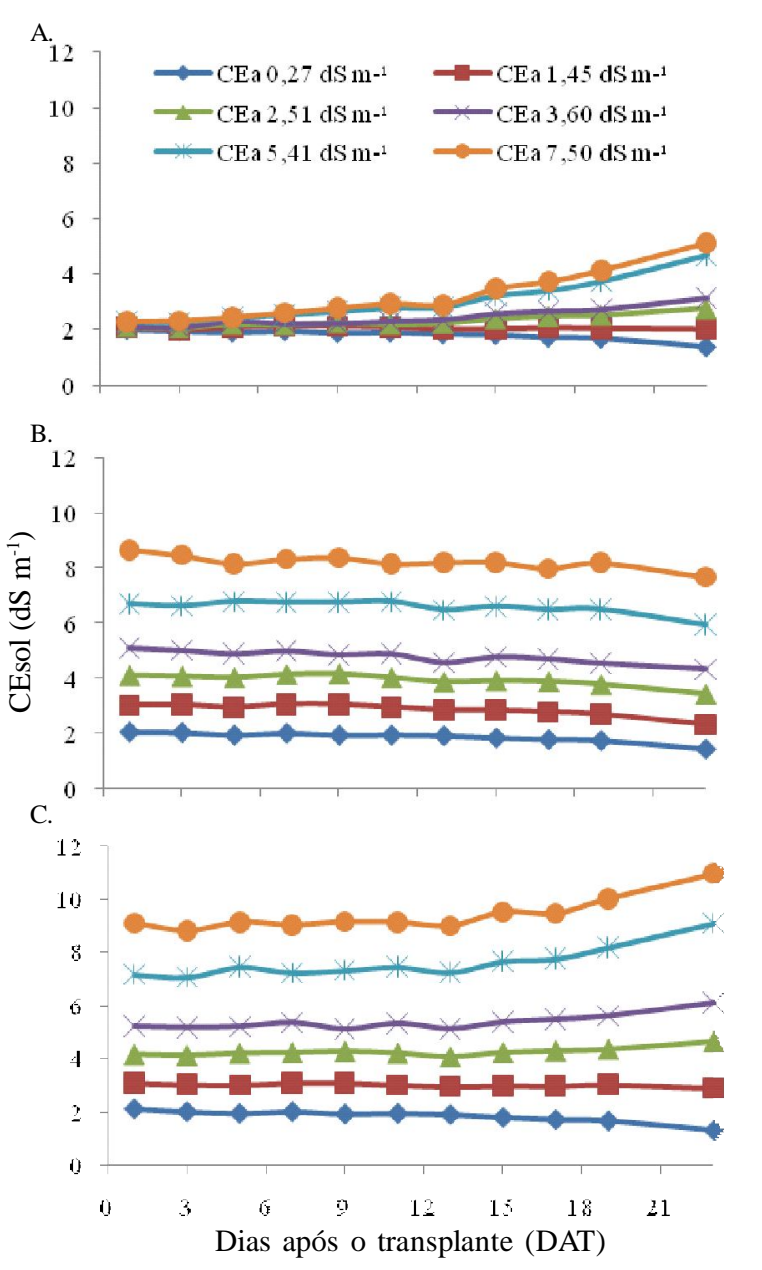

Figura 2. Evolução da condutividade elétrica da solução nutritiva (CEsol) ao longo do ciclo da cultura, nos usos UI - água doce (não salinizada) no preparo da solução nutritiva e água salobra na reposição da evapotranspiração (ETc) (A), U II - água salobra foi utilizada no preparo da solução nutritiva e a reposição da ETc foi feita com água doce (B) e UIII - água salobra, tanto na solução nutritiva como na reposição da ETc (C)

Ressalta-se que nos diferentes tipos de uso de águas salobras não se repuseram os nutrientes absorvidos pelas culturas, em razão da alta disponibilidade de solução nutritiva por planta (4,6 L), sabendo-se que a disponibilidade preconizada comercialmente é de 1 a 2 L por planta.

Para os demais tratamentos do tipo de uso UI, a tendência foi de aumento da salinidade da solução nutritiva, em decorrência do aporte de íons ao longo do ciclo, resultado também obtido por Soares et al. (2007) e Soares et al. (2010). Este aumento da salinidade caracterizou a salinização da solução nutritiva, sendo mais inten so na segunda quinzena do ciclo das culturas, fase em que o consumo hídrico e, por conseguinte, o aporte de íons, foram mais elevados.

Nos tipos de uso UII e UIII, a salinidade inicial foi variável entre os tratamentos. Para a testemunha, a salinidade inicial da solução foi de 2,19 dS m m $^{-1}$, ou seja, dependente apenas dos sais fertilizantes racionalmente quantificados visando à produção potencial das culturas. Para os demais tratamentos a salinidade inicial foi decorrente tanto da presença dos sais 
fertilizantes quanto da salinidade da água devido à adição de $\mathrm{NaCl}$.

Neste sentido, para os tratamentos que tinham CEa de 1,45, 2,51, 3,60, 5,41, e 7,5 dS m $\mathrm{m}^{-1}$, os valores iniciais de salinidade da solução nutritiva foram, respectivamente: $3,29,4,19,5,01,6,86$, e $8,33 \mathrm{dS} \mathrm{m}^{-1}$. Como no UII a reposição das perdas por evapotranspiração foi efetuada com água doce, a salinidade desses tratamentos tendeu a ser constante. Apenas na segunda quinzena do ciclo se registrou uma pequena tendência à diminuição da salinidade da solução nutritiva, o que era esperado em decorrência do consumo de nutrientes não repostos ao longo do cultivo (Figura 2B). Este comportamento também foi observado por Soares et al. (2010), em estudo realizado com água doce na reposição da evapotranspiração e no qual se reservou a água salobra para o preparo da solução nutritiva em sistema hidropônico. Costa et al. (2001), estudando o efeito da condutividade elétrica da solução nutritiva sobre a produção de alface hidropônica, também verificaram redução da condutividade elétrica da solução nutritiva na última semana de cultivo.

Já no UIII, em que a reposição foi realizada com água salobra, a tendência foi de aumento da salinidade da solução nutritiva (Figura 2C) ao longo do ciclo. Este mesmo comportamento foi observado por Santos et al. (2010) e por Paulus et al. (2010), em avaliações com águas salobras na preparação da solução nutritiva e na reposição da evapotranspiração de diferentes cultivares de alface; apenas para a água com condutividade elétrica de $1,45 \mathrm{dS} \mathrm{m}^{-1}$, a salinidade da solução nutritiva passou de 3,09, no início do ciclo, para 2,91 dS m${ }^{-1}$ no momento da colheita, mantendo-se praticamente constante.

$\mathrm{O}$ aumento da salinidade se explica pela acumulação de íons não absorvidos pelas plantas de alface devido à reposição do volume de água evapotranspirado com água salobra.

Não foram registradas diferenças significativas entre os níveis de salinidade para as variáveis de produção (Tabela 2) quando se utilizou água salobra apenas na reposição da evapotranspiração (UI). Soares et al. (2010) atribuíram esse tipo de resultado à salinização gradual, proporcionada pelo procedimento do uso tipo UI, e ao curto ciclo da alface. Na Figura 3 se apresenta o aspecto visual das plantas submetidas ao tipo de uso UI.

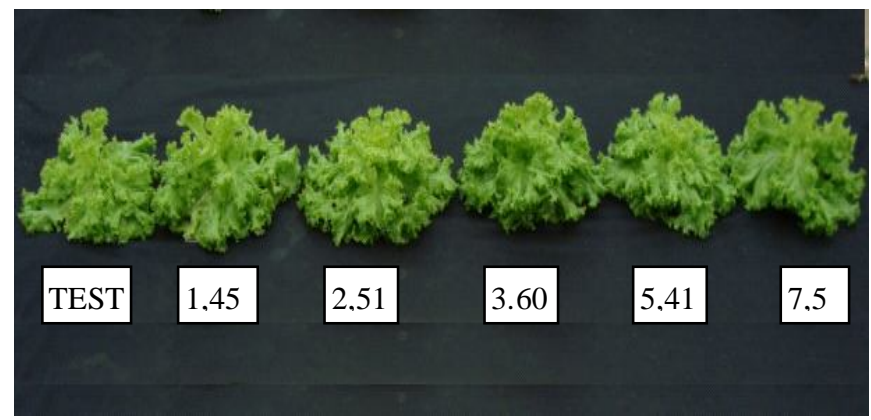

Figura 3. Plantas de alface submetidas aos níveis de salinidade em dS m ${ }^{-1}$ no tipo de uso U I - água doce (não salinizada) no preparo da solução nutritiva e água salobra na reposição da evapotranspiração (ETc)

De fato, o estabelecimento de níveis de salinidade já altos desde o início do cultivo, como decorrência do manejo dos tipos de uso UII e UIII, tendeu a uma redução linear da MFF, da MFC e da MFPA (Tabela 2). Os valores da razão (a/b) entre os coeficientes angular (a) e linear (b) das equações ajustadas apresentadas na Tabela 2 foram maiores no tipo de uso UIII que no tipo de uso UII para as variáveis de MFF e MFPA, ou seja, para cada aumento unitário da salinidade da água (em $\mathrm{dS} \mathrm{m}^{-1}$ ), as estimativas de reduções percentuais registradas nos tipos de uso U2 e U3, respectivamente, foram de 4,64 e $6,84 \%$ para a massa de matéria fresca da folha e de 4,99 e $7,00 \%$ para massa de matéria fresca da parte aérea.

Tabela 2. M odelos da análise de regressão, coeficientes de determinação $\left(R^{2}\right)$ e coeficientes de variação (CV) das variáveis de produção da alface 'Verônica', em função do tipo de uso da água salobra e da salinidade (CEa)

\begin{tabular}{|c|c|c|c|}
\hline \multirow{2}{*}{ Variáveis de produção ${ }^{1}$} & \multicolumn{3}{|c|}{ Tipo de uso ${ }^{2}$} \\
\hline & UI & UII & UIII \\
\hline MFF & $\begin{array}{c}y=n s \\
C V=11,19 \%\end{array}$ & $\begin{array}{c}y=-12,444 C E a^{*} *+267,96 * * \\
R^{2}=0,5649 ; \quad C V=12,30 \%\end{array}$ & $\begin{array}{c}y=-23,267 C^{2} a^{*} *+339,73^{* *} \\
R^{2}=0,8904 ; C V=10,86 \%\end{array}$ \\
\hline MFC & $\begin{array}{c}y=n s \\
C V=9,68 \%\end{array}$ & $\begin{array}{c}y=-2,7685 C E C^{*} *+36,32 * * \\
R^{2}=0,6785 ; C V=18,05 \%\end{array}$ & $\begin{array}{c}y=-3,6605 C \mathrm{Ea}^{* *}+44,74 * * \\
\mathrm{R}^{2}=0,7591 ; C V=16,28 \%\end{array}$ \\
\hline MFPA & $\begin{array}{c}y=n s \\
C V=9,61 \%\end{array}$ & $\begin{array}{c}y=-15,212 C E a^{*} *+304,28 * * \\
R^{2}=0,5649 ; C V=12,30 \%\end{array}$ & $\begin{array}{c}y=-26,928 C C^{*} * *+384,48 * * \\
R^{2}=0,8986 ; C V=11,05 \%\end{array}$ \\
\hline $\mathrm{CP}$ & $\begin{array}{c}y=n s \\
C V=5,93 \%\end{array}$ & $\begin{array}{c}y=-1,087 C E a * *+45,34 * * \\
R^{2}=0,6616 ; \quad C V=4,73 \%\end{array}$ & $\begin{array}{c}y=-2,0646 C \mathrm{CEa}^{*} *+47,70 * * \\
\mathrm{R}^{2}=0,7004 ; C V=8,43 \%\end{array}$ \\
\hline CC & $\begin{array}{c}y=n s \\
C V=7,70 \%\end{array}$ & $\begin{array}{c}y=-0,5982 C E a^{*} *+13,42 * * \\
R^{2}=0,5706 ; C V=11,58 \%\end{array}$ & $\begin{array}{c}y=-0,5979 \text { CEa** }^{2}+14,37 * * \\
R^{2}=0,4950 ; \quad C V=12,43 \%\end{array}$ \\
\hline CR & $\begin{array}{c}y=n s \\
C V=6,97 \%\end{array}$ & $\begin{array}{c}y=n s \\
C V=12,14 \%\end{array}$ & $\begin{array}{c}y=n s \\
C V=15,69 \%\end{array}$ \\
\hline MSF & $\begin{array}{c}y=n s \\
C V=13,60 \%\end{array}$ & $\begin{array}{c}y=n s \\
C V=12,93 \%\end{array}$ & $\begin{array}{c}y=n s \\
C V=9,78 \%\end{array}$ \\
\hline MSR & $\begin{array}{c}y=n s \\
C V=9,61 \%\end{array}$ & $\begin{array}{c}y=n s \\
C V=9,78 \%\end{array}$ & $\begin{array}{c}y=n s \\
C V=14,23 \%\end{array}$ \\
\hline MSPA & $\begin{array}{c}y=n s \\
C V=12,76 \%\end{array}$ & $\begin{array}{c}y=n s \\
C V=14,76 \%\end{array}$ & $\begin{array}{c}y=n s \\
C V=9,57 \%\end{array}$ \\
\hline
\end{tabular}

${ }_{1}^{1}$ MFF - massa de matéria fresca das folhas; MFC - massa de matéria fresca do caule; MFPA - massa de matéria fresca da parte aérea; CP - circunferência da planta; CC - comprimento do caule; CR - comprimento da raiz; MSF - massa de matéria seca das folhas; MSR - massa de matéria seca da raiz; MSPA - massa de matéria seca da parte aérea

2 UI - água doce para preparo da solução nutritiva (SN) e água salobra para reposição da evapotranspiração (ETC); UII - água salobra para preparo da SN e água doce para reposição da ETc; UIII - água salobra para preparo da SN e reposição da ETc

** representa significativo a $1 \%$ de probabilidade; ns representa não significância a $5 \%$ de probabilidade 
As perdas relativas encontradas no presente estudo são menores que as registradas por Paulus et al. (2010), para a cultivar 'Verônica', nas condições de Piracicaba, São Paulo. Analisando os dados desses autores, pode-se estimar uma perda de MFPA de 7,80\%, para cada aumento unitário da salinidade da água, em dS m${ }^{-1}$. Santos et al. (2010) estimaram uma redução ainda maior, da ordem de $17,06 \%\left(\mathrm{dS} \mathrm{m}^{-1}\right)^{-1}$ para a alface crespa 'Vera', mas com águas salobras de origem subterrânea e nas condições semiáridas de Ibimirim, Pernambuco.

A diferença das reduções percentuais estimadas entre os tipos de uso UII e UIII foi de aproximadamente $2 \%\left(\mathrm{dS} \mathrm{m}^{-1}\right)^{-1}$ para a MFF e MFPA. Esta diferença entre ambos os usos também foi observada para a circunferência da planta (CP); já para a MFC e o comprimento do caule (CC), a diferença de redução relativa para os dois tipos de uso foi menor, chegando a ser inferior a $1 \%$. Essas diferenças entre os usos UII e UIII devem ser bem condicionadas às condições climáticas e ao ciclo da cultura; assim, para as condições de maior consumo hídrico acumulado, espera-se maior salinização no uso UIII e, portanto, maior diferença de produção em relação ao uso UII. A precocidade da alface hidropônica (colhida 24 dias após o transplantio) explica as diferenças relativamente baixas entre os tipos de uso UII e UIII no presente trabalho.

O aumento da salinidade da solução com a utilização de água salobra não afetou significativamente o comprimento (CR) nem a massa de matéria seca da raiz (MSR), em todos os tipos de uso estudados, demonstrando que a redução do crescimento das plantas foi mais decorrente do efeito da salinidade sobre a parte aérea que sobre o sistema radicular. Tas et al. (2005), estudando a resposta da alface hidropônica à salinidade produzida por $\mathrm{NaCl}$ e $\mathrm{CaCl}_{2}$, também não observaram efeito significativo da salinidade no comprimento radicular. Nos trabalhos já citados de Paulus et al. (2010) e Soares et al. (2007) também não se registrou efeito da salinidade da água sobre o sistema radicular da alface 'Verônica' em hidroponia NFT. De maneira geral, os trabalhos com águas salobras em hidroponia não têm registrado diminuição do sistema radicular da alface, contrariando trabalhos desenvolvidos em condições de solo, como o de Viana et al. (2004).

Para a MSF e MSPA não ocorreu efeito significativo em nenhum dos tipos de uso estudados (Tabela 2). Esses resultados divergem dos obtidos por Soares et al. (2010), Paulus et al. (2010) e Santos et al. (2010a e b), que reportaram redução linear da massa de matéria seca da parte aérea da alface hidropônica, em decorrência do aumento da salinidade da água. As referidas discrepâncias podem estar associadas ao fato de que, no presente trabalho, a massa de matéria fresca pode ter sido mais influenciada pela diminuição do teor de água (Figura 4) nos tecidos e pelo aumento no teor de matéria seca, em função do aumento da salinidade, em comparação com os outros trabalhos citados.

De fato, na Figura 4 é mostrado que o aumento da salinidade da água reduziu o teor de água na parte aérea das plantas; assim, após a secagem em estufa, os tecidos submetidos aos tratamentos menos salinos perderiam mais água. Além disso, o aspecto coriáceo das plantas submetidas aos níveis mais altos de salinidade pode ser a expressão de tecidos mais espessos e

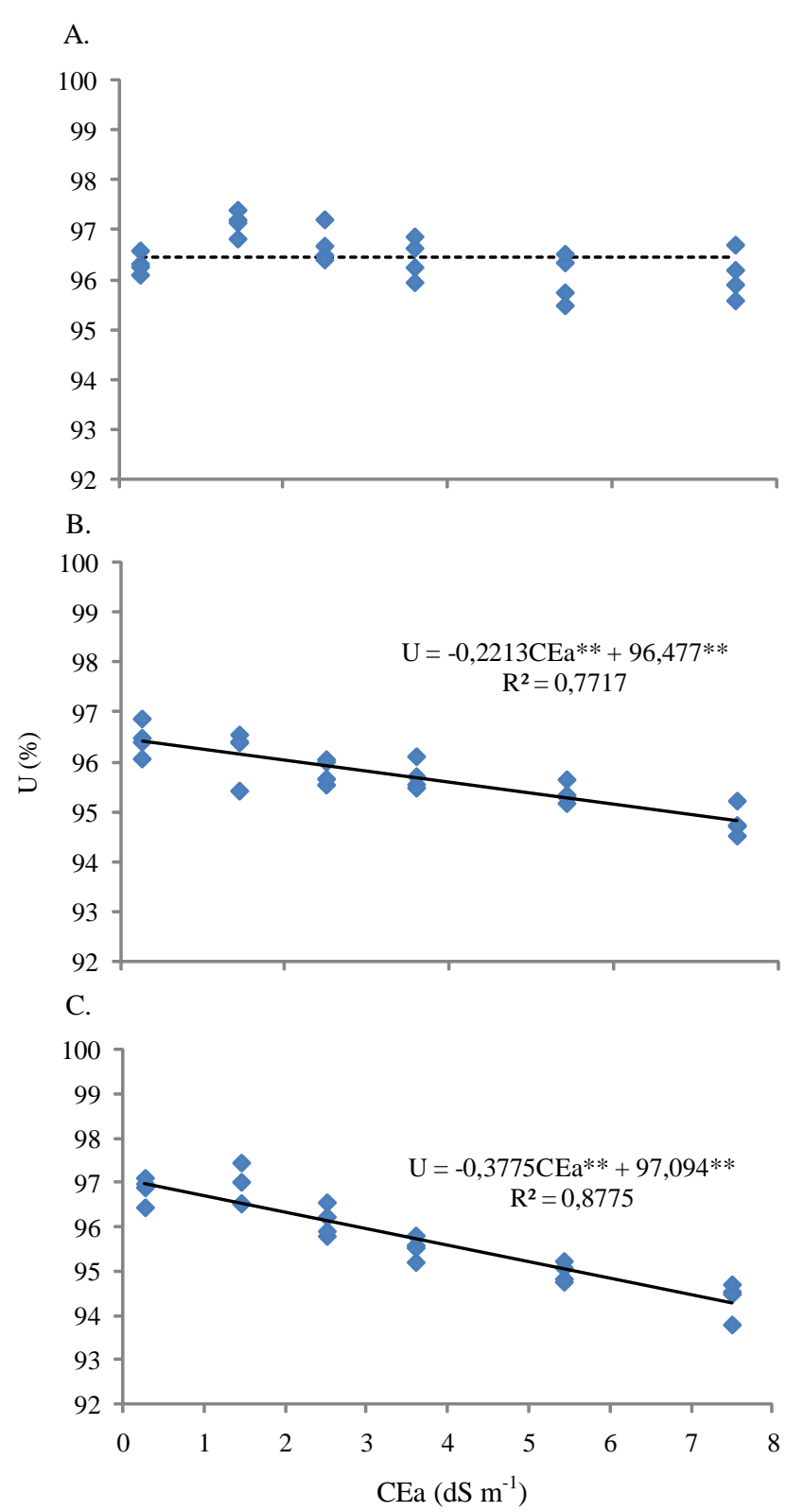

Figura 4. Teor de água na parte aérea (U ), em função da salinidade da água nos tipos de U so I - água doce para preparo da solução nutritiva (SN) e água salobra para reposição da evapotranspiração (ETC) (A), U so II - água salobra para preparo da SN e água doce para reposição da ETc (B) e U so III - água salobra para preparo da SN e reposição da ETc (C)

mais ricos em substâncias orgânicas e inorgânicas por unidade de área foliar; o que poderia reduzir as diferenças de massa de matéria seca em relação às plantas submetidas aos menores níveis de salinidade. Unlukara et al. (2008), estudando a resposta da alface crespa em diferentes níveis da salinidade da água de irrigação $\left(0,75\right.$ a $\left.7,0 \mathrm{dS} \mathrm{m}{ }^{-1}\right)$, também notaram aumento do teor de matéria seca da planta com o aumento da salinidade. Esses fatores podem explicar a menor redução relativa da produção da alface hidropônica submetida ao aumento da salinidade quando se estuda a massa de matéria seca e não a massa de matéria fresca. Isto pode ser notado também nas investigações de Soares et al. (2010), Santos et al. (2010a e b) e Paulus et al. 
Tabela 3. Produtividade relativa dos valores médios observados, em relação à testemunha, para as variáveis massas de matéria fresca da parte aérea (M FPA) e das folhas (M FF) e massa de matéria seca da parte aérea (MSPA), das folhas (MSF) e das raízes (MSR) submetidas a diferentes níveis de salinidade da água $\left(\mathrm{CE}_{\mathrm{a}}\right)$

\begin{tabular}{|c|c|c|c|c|c|c|c|c|c|c|c|c|c|c|c|}
\hline \multirow{2}{*}{$\begin{array}{c}\text { CEa } \\
\left(\mathrm{dSm}^{-1}\right)\end{array}$} & \multicolumn{3}{|c|}{ MFPA (\%) } & \multicolumn{3}{|c|}{ MFF (\%) } & \multicolumn{3}{|c|}{ MSPA (\%) } & \multicolumn{3}{|c|}{ MSF (\%) } & \multicolumn{3}{|c|}{ MSR (\%) } \\
\hline & UI & UII & UIII & UI & UII & UIII & UI & UII & UIII & UI & UII & UIII & UI & UII & UIII \\
\hline 0,27 & 100,0 & 100,0 & 100,0 & 100,0 & 100,0 & 100,0 & 100,0 & 100,0 & 100,0 & 100,0 & 100,0 & 100,0 & 100,0 & 100,0 & 100,0 \\
\hline 1,45 & 104,5 & 98,9 & 101,2 & 105,2 & 100,6 & 101,0 & 81,3 & 103,4 & 102,0 & 78,4 & 104,7 & 98,9 & 103,5 & 98,7 & 98,7 \\
\hline 2,51 & 102,6 & 101,5 & 87,8 & 103,1 & 102,1 & 88,1 & 92,6 & 118,9 & 109,7 & 91,2 & 122,1 & 109,3 & 100,8 & 111,6 & 107,0 \\
\hline 3,60 & 99,9 & 96,3 & 77,6 & 100,5 & 98,2 & 77,9 & 96,6 & 115,6 & 112,7 & 95,7 & 120,0 & 113,1 & 111,8 & 115,0 & 112,2 \\
\hline 5,41 & 97,1 & 85,2 & 64,5 & 97,8 & 98,2 & 64,9 & 105,1 & 110,2 & 105,2 & 104,9 & 115,0 & 106,2 & 115,6 & 123,6 & 116,7 \\
\hline 7,50 & 102,9 & 59,4 & 50,8 & 104,5 & 62,6 & 52,2 & 109,2 & 86,4 & 92,9 & 109,5 & 92,6 & 95,4 & 126,7 & 113,8 & 112,5 \\
\hline
\end{tabular}

UI - água doce para preparo da solução nutritiva (SN) e água salobra para reposição da evapotranspiração (ETc); UII - água salobra para preparo da SN e água doce para reposição da ETc; UIII - água salobra para preparo da SN e reposição da ETc

(2010).

Deve-se registrar que os coeficientes de variação da MSPA foram inferiores a $15 \%$ (Tabela 2), o que demonstra que a não significância do efeito da salinidade da água para a MSPA não foi decorrente de fatores não controláveis.

Para a MFPA, verificou-se perda de $40,6 \%$ para o uso tipo UII e de 49,2\% para o uso tipo UIII, ao se comparar a água de maior salinidade $\left(7,5 \mathrm{dS} \mathrm{m} \mathrm{m}^{-1}\right)$ com a testemunha. Em relação à MFF, a perda registrada no UII foi de $37,4 \%$, enquanto no UIII o decréscimo foi de 47,8\% (Tabela 3).

Como o interesse comercial da alface é a parte aérea, expressa na MFPA, pode-se obter uma produção satisfatória (redução inferior a 15\% da produtividade da testemunha) nos tipos de uso UII e UIII, até os níveis de salinidade 5,41 dS m${ }^{-1}$ e $2,51 \mathrm{dS} \mathrm{m}^{-1}$, respectivamente.

Este resultado pode indicar, ao produtor, a possibilidade de uso exclusivo de água salobra para o cultivo de alface em hidroponia, se em sua propriedade estiver disponível água salobra com salinidade de até $2,51 \mathrm{dS} \mathrm{m}^{-1}$, economizando a água doce para outros fins, como a dessedentação.

Não foram detectados sintomas de toxidez ou deficiência mineral nas plantas de alface nos três tipos de uso de água salobra, mesmo quando submetidas aos níveis mais altos de salinidade da água de reposição, o que pode ser atribuído à característica do sistema NFT, com a passagem da água apenas na zona radicular, sem o típico molhamento das folhas verificado em muitos sistemas convencionais de irrigação. Isto evita a absorção foliar, que rapidamente faz com que íons tóxicos se concentrem nas folhas, surgindo daí os sintomas de clorose e necrose foliares. Usualmente, sintomas de injúrias foliares, como queima dos bordos e do limbo foliares, são bem reportados em plantas submetidas às águas salobras (Santos et al., 2010).

Entretanto, nos tipos de uso UII e UIII, foram observadas plantas menores, com folhas mais coriáceas e tonalidade de verde mais escuro, quando as plantas foram submetidas aos níveis mais elevados de salinidade (Figura 5A e 5B), embora esses sintomas não tenham depreciado a qualidade do produto. Essas características também foram verificadas por outros autores (Paulus et al., 2010; Soares et al., 2010; Tesi et al., 2003; Shannon et al., 1983).

Neste sentido, mesmo com a água de maior salinidade $(7,5$ $\mathrm{dS} \mathrm{m}^{-1}$ ) e com o tipo de uso mais crítico (UIII), pode-se ter viabilidade técnica econômica de produção. Se a margem de lucro da alface hidropônica for alta, a produção relativa de $50,8 \%$ de MFPA (Tabela 3 ) poderá ser viável; por outro lado, se o produtor desejar, pode compensar a redução da produção relativa aumentando a densidade de plantas por $\mathrm{m}^{2}$.
A.

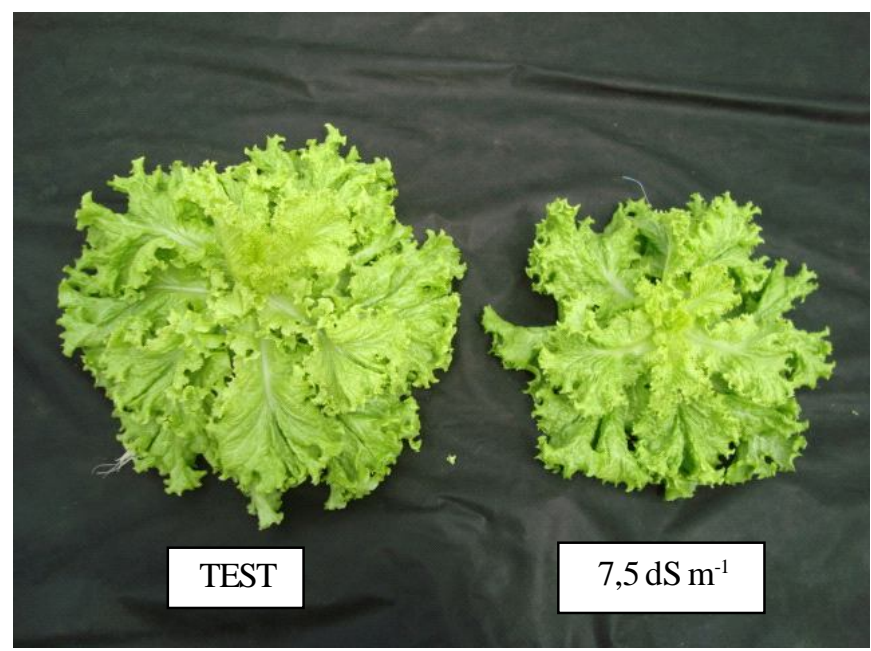

B.

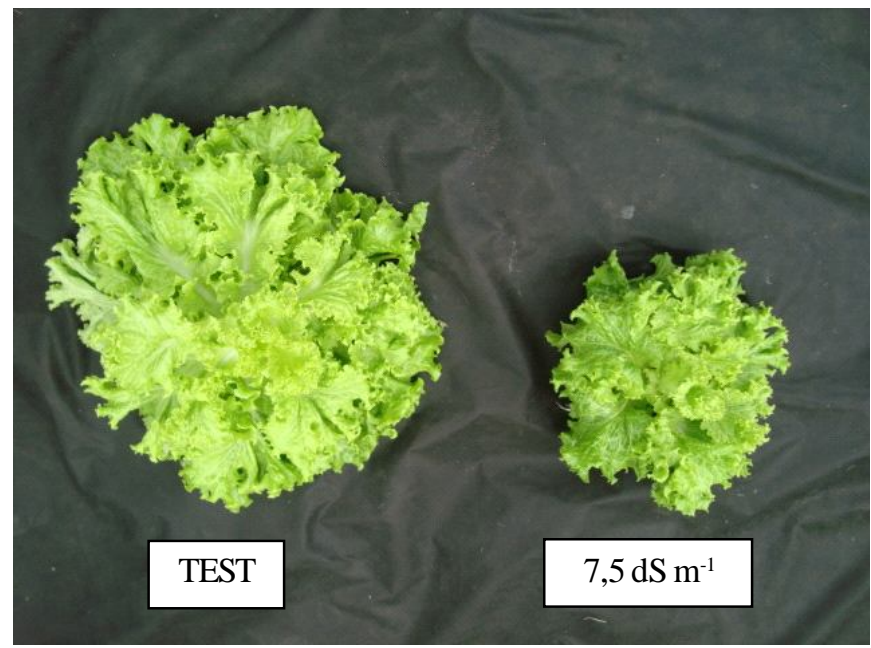

Figura 5. Diferenças visuais entre plantas de alface Verônica produzidas com água doce (TEST) e o nível mais

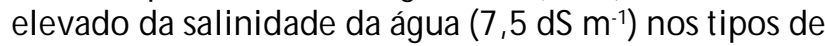
uso UII - água salobra para preparo da solução nutritiva (SN ) e água doce para reposição da evapotranspiração (ETC) (A) e U III - água salobra para preparo da SN e reposição da ETc (B)

Obviamente, só após um estudo de viabilidade econômica se poderá nortear recomendações mais categóricas e conclusivas, mas o fato é que os índices de redução quantitativa e qualitativa da alface produzida em hidroponia 
NFT com águas salobras apontam positivamente para o aproveitamento racional de água subterrânea salobras do semiárido brasileiro.

\section{Conclusões}

1. O uso de água salobra no preparo da solução nutritiva proporcionou redução da produção da alface 'Verônica' com o aumento da salinidade da água;

2. A utilização de água salobra na reposição da evapotranspiração combinada com o uso de água doce no preparo da solução nutritiva não foi prejudicial às características de produção e qualidade visual da alface;

3. Quando forem disponíveis águas doce e salobras, é mais produtivo empregar a doce para o preparo da solução nutritiva, reservando as salobras para a reposição do consumo hídrico no cultivo de alface hidropônica;

4. Com o uso de águas salobras no preparo da solução nutritiva, foram observados aspecto coriáceo, nanismo e coloração verde-escuro nas plantas, para os níveis mais altos de salinidade da água.

5. O uso exclusivo de águas salobras reduz a produção de alface hidropônica em $7 \%$ por acréscimo unitário na salinidade da água (em dS m $\mathrm{m}^{-1}$ ), mas não produz sintomas visuais deletérios à sua qualidade.

\section{Agradecimentos}

Os autores agradecem à Fundação de Amparo à Pesquisa do Estado da Bahia (FAPESB) e ao Conselho Nacional de Desenvolvimento Científico e Tecnológico $(\mathrm{CNPq})$, pelo apoio financeiro para execução dos projetos.

\section{LITERATURACITADA}

Almeida, O. A. Informações meteorológicas do CNP. Cruz das Almas, BA: Embrapa CNPMF. 1999.35p. Documentos, 34.

Amorim, D. M. B.; Notaro, I. A.; Furtado, D. A.; Gheyi, H. R.; Baracuhy, J. G. V. Avaliação de diferentes níveis de salinidade da água utilizada na produção de forragem hidropônica de milho. Revista Brasileira de Engenharia Agrícola e Ambiental, v.9, p.339-342, 2005.

Audry, P.; Suassuna, J. A salinidade das águas disponíveis para a pequena irrigação no sertão nordestino: Caracterização, variação sazonal, limitações de uso. Recife: CNPq, 1995. 128 p.

Ayers, R.S.; Westcot, D. W. A qualidade da água na agricultura. 2.ed. Campina Grande: UFPB, 1999. 153p. Estudos FAO. Irrigação e Drenagem, 29.

Casaroli, D.; Fagan, E. B.; Santos, O. S.; Bonnecarrère, R. A. G.; Nogueira Filho, H. Desempenho de onze cultivares de alface em duas formas diferentes de canais de cultivo, no sistema hidropônico. Revista da Faculdade de Zootecnia, Veterinária e Agronomia, v.10, p.114-123, 2003.

Costa,A. M. B.; Melo, J. G. E.; Silva, F. M. Aspectos da salinização das águas do aquífero cristalino no estado do Rio Grande do Norte, Nordeste do Brasil. Águas Subterrâneas, v.20, p.67-82, 2006.
Costa, P. C.; Didone, E. B.; Sesso, T. M.; Cañizares, K. A. L.; Goto, R. Condutividade elétrica da solução nutritiva e produção de alface em hidroponia. Scientia Agrícola, v.58, p.595-597, 2001.

Dias, N. S.; Lira, R. B.; Brito, R. F.; Souza Neto, O. N.; Ferreira Neto, M.; Oliveira, A. M. Produção de melão rendilhado em sistema hidropônico com rejeito da dessalinização de água em solução nutritiva. Revista Brasileira de Engenharia Agrícola e Ambiental, v. 14, p. 755-761, 2010.

Furlani, P. R; Silveira, L. C. P.; Bolonhezi, D.; Faquin, V. Cultivo hidropônico de plantas. Campinas: IAC, 1999. 52p. Boletim técnico, 180.

Martinez, H. E. P. Manual prático de hidroponia. Viçosa: Aprenda Fácil, 2006. 271p.

Paulus, D.; Dourado Neto, D.; Frizzone, J. A.; Soares, T. M. Produção e indicadores fisiológicos de alface sob hidroponia com água salina. Horticultura Brasileira, v.28, p.29-35, 2010.

Rodrigues, L. R. F. Técnicas de cultivo hidropônico e de controle ambiental no manejo de pragas, doenças e nutrição vegetal em ambiente protegido. Jaboticabal: FUNEP, 2002. 762p.

Santos, A. N.; Soares, T. M.; Silva, E. F. de F. e; Silva, D. J. R.; Montenegro, A. A. A. Cultivo hidropônico de alface com água salobra subterrânea e rejeito da dessalinização em Ibimirim, PE. Revista Brasileira de Engenharia Agrícola e Ambiental, v.14, p.961-969, 2010a.

Santos, R. S.; Dias, N. S.; Sousa Neto, O. N.; Gurgel, M. T. Uso do rejeito da dessalinização de água salobra no cultivo da alface (Lactuca sativa L.) em sistema hidropônico NFT. Ciência e Agrotecnologia, v.34, p.983-989, 2010b.

Shannon, M. C.; Mccreigth, J. D.; Draper, J. H. Screening test for salt tolerance in lettuce. Journal of the American Society for Horticulture Science, Mount Vernon, v.108, p. 225-230, 1983.

Soares, T. M.; Duarte, S. N.; Silva, E. F. F.; Melo, R. F.; Jorge, C.A.; Oliveira, A. S. Experimental structure for evaluation of saline water use in lettuce hydroponic production. Irriga, v.14, p.102-114. 2009.

Soares, T. M.; Duarte, S. N.; Silva, E. F. de F. e; Jorge, C. A. Combinação de águas doce e salobra para produção de alface hidropônica. Revista Brasileira de Engenharia Agrícola e Ambiental, v.14, p.705-714, 2010.

Soares, T. M.; Silva, E. F. F.; Duarte, S. N.; Melo, R. F.; Jorge, C. A.; Bonfim-Silva, E. M. Produção de alface utilizando águas salobras em sistema hidropônico. Irriga, v.12, p.235-248, 2007.

Tas, G.; Papadandonakis, N.; Sawas, D. Responses of lettuce (Lactuca sativa L. var. longifolia) grown in a closed hydroponic system to $\mathrm{NaCl}^{-}$or $\mathrm{CaCl}_{2}^{-}$salinity. Journal of Applied Botany and Food Quality Angewandte Botanik, v.79, p.136-140, 2005.

Tesi, R.; Lenzi, A.; Lombardi, P. Effect of salinity and oxygen level on lettuce grown in a floating system. Acta Horticulturae, v.609, p.383-387, 2003.

Unlukara, A.; Cemek, B.; Karaman, S.; Ersahin, S. Response of lettuce (Lactuva sativa var. crispa) to salinity of irrigation water. New Zealand Journal of Crop and Horticultural Science, v.36, p.265-273, 2008.

Viana, S. B. A; Fernandes, P. D.; Gheyi, H. R.; Soares, F. A. L.; Carneiro, P. T. Índices morfofisiolóficos e de produção de alface sob estresse salino. Revista Brasileira de Engenharia Agrícola e Ambiental, v.8, p.23-30, 2004. 